\title{
INVESTIGATION OF FLY ASH AND ACTIVATED CARBON OBTAINED FROM PULVERIZED COAL BOILERS
}

\author{
ANNUAL REPORT
}

September 1, 2004 to September 1, 2005

Dr. Edward K. Levy and Dr. Christopher Kiely

November, 2005

DE - FG26-03NT41796

Energy Research Center

Lehigh University

117 ATLSS Drive

Bethlehem, PA 18015 


\section{DISCLAIMER}

"This report was prepared as an account of work sponsored by an agency of the United States Government. Neither the United States Government nor any agency thereof, nor any of their employees, makes any warranty, express or implied, or assumes any legal liability or responsibility for the accuracy, completeness, or usefulness of any information, apparatus, product, or process disclosed, or represents that its use would not infringe privately owned rights. Reference herein to any specific commercial product, process, or service by trade name, trademark, manufacturer, or otherwise does not necessarily constitute or imply its endorsement, recommendation, or favoring by the United States Government or any agency thereof. The views and opinions of authors expressed herein do not necessarily state or reflect those of the United States Government or any agency thereof."

\section{ACKNOWLEDGEMENTS}

The principal investigators of this project are grateful to the following individuals for their assistance in carrying out the various tasks:

- Zheng Yao, Graduate Student in Mechanical Engineering

- Dr. Andrew Burrows, Electron Microscopy Specialist in Materials Science

- Brian Celeste, Graduate Student in Mechanical Engineering 


\section{ABSTRACT}

One of the techniques for $\mathrm{Hg}$ capture in coal-fired boilers involves injection of activated carbon $(\mathrm{AC})$ into the boiler downstream of the air preheater. $\mathrm{Hg}$ is adsorbed onto the $\mathrm{AC}$ particles and fly ash, which are then both removed in an electrostatic precipitator or baghouse.

This project addresses the issues of $\mathrm{Hg}$ on activated carbon and on fly ash from a materials re-use point of view. It also addresses the possible connection between SCR reactors, fly ash properties and $\mathrm{Hg}$ capture. The project is determining the feasibility of separating AC from fly ash in a fluidized bed and of regenerating the separated $A C$ by heating the $A C$ to elevated temperatures in a fluidized bed. The temperatures needed to drive off the $\mathrm{Hg}$ from the ash in a fluidized bed are also being determined. Finally, samples of fly ash from power plants with SCR reactors for $\mathrm{NO}_{x}$ control, are being analyzed to determine the effect of SCR on the ash. 


\section{TABLE OF CONTENTS}

Page

INTRODUCTION

Objectives 2

EXECUTIVE SUMMARY 3

$\begin{array}{lc}\text { EXPERIMENTAL } & 5\end{array}$

Task 1: Separation of Activated Carbon and Fly Ash in a Fluidized Bed 5

Task 2: Removal of $\mathrm{Hg}$ from Activated Carbon and Fly Ash 7

Task 3: Microstructural and Chemical Analysis of Fly Ash and Activated 8 Carbon

Task 4: Effect of SCR on Ash Properties 9

RESULTS AND DISCUSSION

Task 1: Separation of Activated Carbon and Fly Ash in a Fluidized Bed 10 Additional Testing Underway 13

Task 2: Removal of Hg from Activated Carbon and Fly Ash 13

Task 3(a): Morphologies of Fly-Ash and Activated Carbon 14

Fly Ash/AC Mixture Obtained by Segregation 19

$\begin{array}{ll}\text { Pure Activated Carbon } & 19\end{array}$

Fly Ash With High Unburned Carbon $\quad 20$

$\begin{array}{ll}\text { SUMMARY AND CONCLUSIONS } & 24\end{array}$

Task 1: Separation of Activated Carbon and Fly Ash in a Fluidized Bed $\quad 24$

Task 2: Removal of $\mathrm{Hg}$ from Activated Carbon and Fly Ash 24

Task 3: Morphologies of Fly Ash and Activated Carbon 25

Future Experiments $\quad 25$

$\begin{array}{ll}\text { REFERENCES } & 25\end{array}$ 


\section{LIST OF FIGURES}

$\underline{\text { Figure }}$

Page

$1 \quad$ Laboratory Batch Fluidized Bed.

2 Sketch Showing Layering Technique for Analysis of Carbon Stratification in Fluidized Bed.

3 Vertical Stratification of LOI and $\mathrm{Hg} . \mathrm{V}_{\text {air }}=0.6 \mathrm{~cm} / \mathrm{s}$.

4 Vertical Stratification of $\mathrm{Hg}$ and LOI. $V_{\text {air }}=0.7 \mathrm{~cm} / \mathrm{s}$.

5 Magnitude of Carbon Stratification Versus Superficial Air Velocity.

$6 \quad \mathrm{Hg}$ Content Versus LOI.

$7 \quad$ Bed Temperature Versus Time (High LOI).

$8 \quad \mathrm{Hg}$ Content Versus Bed Temperature (High LOI).

9 Bed Temperature Versus Time (Medium LOI).

11 Bed Temperature Versus Time (Low LOI).

Hg Content Versus Bed Temperature (Low LOI).

13 Critical Temperature Versus LOI.

Top Layer of FA-1 Fly Ash Segregation. Optical Microscopy Image of Typical Pure Activated Carbon Particle. 22 SEM Image of High Unburned Carbon. 


\section{LIST OF TABLES}

$\underline{\text { Table }}$

Page

$1 \quad$ Fly Ash and Activated Carbon Samples Used in Task 3a

19 


\section{INTRODUCTION}

One of the techniques for $\mathrm{Hg}$ capture in coal-fired boilers involves injection of activated carbon (AC) into the boiler downstream of the air preheater. $\mathrm{Hg}$ is adsorbed onto the AC particles and onto the fly ash, which are then both removed in an electrostatic precipitator or baghouse. While field trials with $A C$ injection have demonstrated the ability to remove significant fractions of the $\mathrm{Hg}$ at some units, there are also problems in using $\mathrm{AC}$ for $\mathrm{Hg}$ capture. Activated carbon is relatively expensive, leading to very high projected costs for $\mathrm{Hg}$ capture (Ref. 1, 2). The AC can increase opacity at units with electrostatic precipitators, due to increased particulate loading and the low resistivity of $A C$ particles. The feed rates of $A C$ required to control $\mathrm{Hg}$ can also result in significant increases in the carbon content of the ash. However, fly ash used in concrete must have carbon contents of $4 \%$ or less in order that the concrete have acceptable mechanical properties. This has raised concerns that widespread use of AC for $\mathrm{Hg}$ capture will eliminate concrete as a viable market for re-use of ash, thereby greatly reducing the percentage of coal ash which can be re-used.

Laudal et al. (Ref. 3) reported data from field tests at 4 boilers equipped with SCR reactors in which $\mathrm{Hg}$ emissions were measured with and without the SCR reactors in operation. The results showed that in 3 of the 4 cases, the SCR reactors caused a reduction in gas phase emissions of $\mathrm{Hg}$, but the actual cause of the reduction needs to be determined.

This project addresses the issues of $\mathrm{Hg}$ on activated carbon and on fly ash from a materials re-use point of view. It also addresses the possible connection between $\mathrm{SCR}$ reactors, fly ash characteristics and $\mathrm{Hg}$ capture. The project is determining the feasibility of separating $A C$ from fly ash in a fluidized bed and of regenerating the separated $A C$ by heating the $A C$ to elevated temperatures in a fluidized bed. The project is also determining the temperatures needed to drive off the $\mathrm{Hg}$ from the ash in a fluidized bed. Finally, samples of fly ash from power plants with SCR reactors for $\mathrm{NO}_{x}$ control are being analyzed to determine the effects of SCR on the ash. 


\section{Objectives}

The objectives of this project are as follows:

- Determine the potential for separation of $\mathrm{AC}$ from fly ash in a bubbling fluidized bed

- Determine the temperatures needed to remove $\mathrm{Hg}$ from spent $\mathrm{AC}$ in a bubbling fluidized bed, thereby creating the possibility of recycling regenerated $A C$ back to the boiler

- Determine the temperatures needed to remove $\mathrm{Hg}$ from fly ash in a bubbling fluidized bed

- Determine which components of fly ash are important for Hg capture

- Determine if SCR reactors affect fly ash chemistry in relation to $\mathrm{Hg}$ capture 


\section{EXECUTIVE SUMMARY}

One of the techniques for $\mathrm{Hg}$ capture in coal-fired boilers involves injection of activated carbon (AC) into the boiler downstream of the air preheater. $\mathrm{Hg}$ is adsorbed onto the AC particles and fly ash, which are then both removed in an electrostatic precipitator or baghouse.

This project addresses the issues of $\mathrm{Hg}$ on activated carbon and on fly ash from a materials re-use point of view. It also addresses the possible connection between $\mathrm{SCR}$ reactors, fly ash properties and $\mathrm{Hg}$ capture. The project is determining the feasibility of separating AC from fly ash in a fluidized bed and of regenerating the separated $A C$ by heating the $A C$ to elevated temperatures in a fluidized bed. The temperatures needed to drive off the $\mathrm{Hg}$ from the ash in a fluidized bed are also being determined. Finally, samples of fly ash from power plants with SCR reactors for $\mathrm{NO}_{x}$ control, are being analyzed to determine the effect of SCR on the ash.

Progress made during the 2004-2005 project year is described in the following paragraphs:

Additional separation experiments were performed on the AC/fly ash mixture to expand the range of carbon contents between the top and bottom layers of the fluidized bed. Analyses of both carbon and mercury contents of the samples obtained from these tests show a strong linear relationship between $\mathrm{Hg}$ and carbon content, with the $\mathrm{Hg}$ content approaching zero as the carbon goes towards zero.

Elevated temperature fluidized bed experiments were performed on the low carbon content mixture from the bottom layers of the fluidized bed, on the high carbon content mixture from the top layers of the fluidized bed and on AC/ash mixture with average carbon content. All behaved qualitatively the same way, with a constant $\mathrm{Hg}$ content until a critical temperature was reached and then with rapidly decreasing $\mathrm{Hg}$ content as the temperature was increased to higher levels. The critical temperature was found to be a linear function of carbon content, increasing from $330^{\circ} \mathrm{C}$ at $17 \% \mathrm{LOI}$ to $370^{\circ} \mathrm{C}$ at $33 \% \mathrm{LOI}$. The temperature at which all of the $\mathrm{Hg}$ was removed is in the 450 to $500^{\circ} \mathrm{C}$ range.

Four ash and activated carbon samples were evaluated by Light Optical and Scanning Electron Microscopy during the 2004-2005 project year. SEM studies of the fly ash/AC mixture obtained from the fluidized bed segregation experiments showed marked differences between the materials from the top and bottom layers of the fluidized bed. The top layer is dominated by large, irregularly shaped particles while the bottom layer has more spherical high-mineral content particles. This finding is consistent with the physical mechanism of segregation which results in denser, smaller particles moving downward towards the distributor and lighter, larger particles floating at the top of the bed.

Light Optical Microscopy images of pure activated carbon particles showed them to be irregular in shape and filled with voids. Light Optical Microscopy studies were also 
performed on a pure fly ash with high carbon content and these showed the naturally occurring carbon in fly ash has a similar internal structure to pure activated carbon.

A barrel of an activated carbon/fly ash mixture obtained from a $\mathrm{Hg}$ capture test at a second boiler was obtained at the end of the 2004-2005 project year. Tasks 1, 2, and 3 analyses will be performed on the material in the coming months. 


\section{EXPERIMENTAL}

This project is, predominately, an experimental study, involving experiments in fluidized beds and laboratory analyses of activated carbon and fly ash by electron microscopy methods and other analytical techniques.

Task 1: Separation of Activated Carbon and Fly Ash in a Fluidized Bed. Because of the strong solid phase mixing and gas-solids interactions which occur in a bubbling fluidized bed operated at gas velocities well above minimum fluidization, fluidized beds are in widespread use in industry for applications such as heat exchangers, combustors, gasifiers, chemical reactors, and solids dryers. However, at superficial gas velocities just slightly above minimum bubbling, the solids do not mix well, and as a result particle segregation occurs in the vertical direction, with the more dense particles settling downward towards the distributor and the lowest density particles moving towards the free surface of the bed (Ref. 4 and 5).

All of the fluidized bed experiments being performed in this project are being carried out with acoustic excitation of the bed material to improve the mixing and segregation of the fly ash and activated carbon. The activated carbon separation experiments are being performed with spent mixtures of $A C$ and fly ash generated during field trials at pulverized coal power plants involving $\mathrm{Hg}$ capture using injected AC.

The separation experiments are being carried out in a $15 \mathrm{~cm}$ diameter batch fluidized bed operating with room temperature air as the fluidizing gas. The bed has a porous plate distributor, is equipped with a loudspeaker above the freeboard, is instrumented with a rotameter to measure air flow rate and a microphone to measure sound pressure level in the bed. The laboratory setup is similar to that illustrated in Figure 1. 

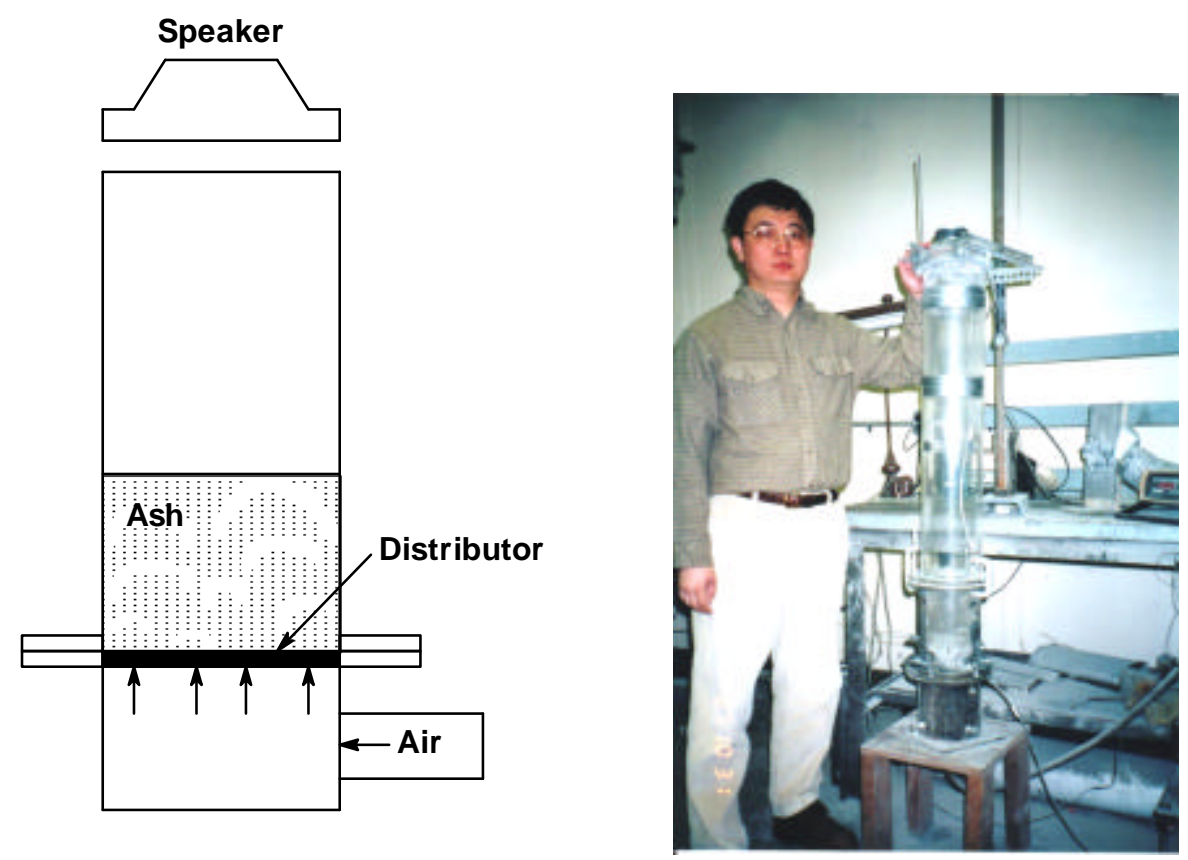

Figure 1: Laboratory Batch Fluidized Bed.

Each experiment is performed by first loading the material into the bed vessel, turning on the sound and air flow, fluidizing at the desired operating conditions for several minutes, abruptly turning off the air and then the sound, and then carefully vacuuming out thin layers of the bed material, with each layer captured in a small filter bag (Figure 2). Each layer is then weighed and analyzed to determine total carbon content. The amounts of naturally occurring unburned carbon in the ash and of the activated carbon in each sample collected from the bed will also be determined. The experiments are being carried out with various air velocities to determine the combination of process conditions which yields the sharpest separation. 


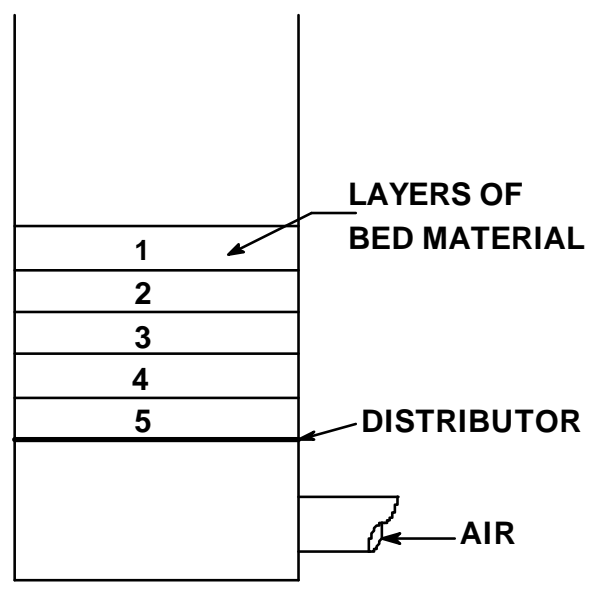

Figure 2: Sketch Showing Layering Technique for Analysis of Carbon Stratification in Fluidized Bed.

Task 2: Removal of $\mathrm{Hg}$ From Activated Carbon and Fly Ash. This task is determining the potential for removing $\mathrm{Hg}$ from spent activated carbon and fly ash using a heated bubbling fluidized bed.

The experiments are being performed in a $15 \mathrm{~cm}$ diameter batch fluidized bed equipped with an in-bed cylindrical electrical resistance heating element to raise the temperature of the bed material to temperatures in excess of $400^{\circ} \mathrm{C}$. As with the equipment used in the previous task, this bed is fluidized with air, and it has a loud speaker above the bed vessel to allow acoustic excitation of the bed material. Thermocouples immersed in the bed are used to measure bed temperature, and air flow rate is measured with a rotameter.

The experimental procedure involves loading the material to be tested into the bed, turning on the loud speaker and the room temperature fluidization air, and then turning on the in-bed electrical heater. As the bed material gradually heats up, small samples of material are removed from the bed. This process is continued until the maximum desired temperature is reached. After being cooled, the samples are analyzed for Hg content using Atomic Absorption Spectroscopy. The data are then arranged in the form of $\% \mathrm{Hg}$ removal as a function of bed temperature. 
Task 3: Microstructural and Chemical Analysis of Fly Ash and Activated Carbon. The experiments in Tasks 1 and 2 require microstructural and spectroscopic analysis of fly ash and AC samples. Specimens of fly ash and AC produced by the Task 1 separation experiments are being subjected to some or all of the following types of analyses:

- Particle Identification by Morphological Observation - Scanning Electron Microscopy (SEM) on a systematic matrix of samples is being carried out on an FEI XL30 environmental scanning electron microscope equipped with an EDS spectrometer. We are attempting to determine the relative proportions of fly ash-to-unburnt C-to-AC in the mixtures created by the fractionation experiments in Task 1(a) because the spherical melted fly ash particles have a visibly different morphology from the $A C$ and unburnt carbon particles. It is also possible to distinguish the various particle types by point EDS analyses and utilizing the fact that the fly ash contains $\mathrm{Si}, \mathrm{Fe}, \mathrm{S}$ and $\mathrm{Al}$ in addition to $\mathrm{C}$ and $\mathrm{Hg}$. In fact, EDS chemical mapping of the binary fly ash/AC mixture in the XL30 SEM is a potential method for producing qualitative visual maps of the relative proportions of fly ash, unburnt carbon and AC. This will allow us to visualize the residual amount of $A C$ in the fly ash after separation in the fluidized bed.

- TEM analysis of the Fly Ash/AC mixtures - samples of the fly ash/AC powders have been dry dispersed and supported on holey carbon films for TEM examination. A 200kV JEOL 2000FX TEM which is equipped with EDS and EELS is being used for the analysis. A combination of high resolution imaging, electron diffraction and EDS point analyses is being used to characterize the mineral constituents that make up the rapidly solidified fly ash particles, which contain silica, alumina and iron sulfites and unburnt carbon. We have attempted to use EDS analysis to determine whether $\mathrm{Hg}$ is preferentially associated with any of these phases or if it is uniformly distributed on the surface of the fly ash. However the $\mathrm{Hg}$ levels of the samples examined to date have been below the EDS detectability limit of the instrument. 
- Light Optical Microscopy Analysis of Fly Ash and Activated Carbon - Light Optical Microscopy is a powerful tool useful for visualizing surface features. Although an optical microscope is not powerful enough to visualize particles in the micron size range and under, it still provides a simple and direct tool to examine the macroscopic features of the fly ash and activated carbon particles.

Black and white images were taken with the camera attached to a Nikon Metaphot photo micrographic microscope. Objective lenses of 5X,10X, 20X and 50X were used in order to obtain the desired magnification levels when imaging fly ash and activated carbon particles. A length scale is shown on each image that was taken.

- $\quad \mathrm{Hg}$ Content Measurement - The total $\mathrm{Hg}$ content of the samples is only around 20-50ppm level at maximum, so a rather sensitive quantitative composition analysis technique will be required. Atomic Emission Spectroscopy (AES) and/or Atomic Absorption Spectroscopy (AAS) are being used to quantitatively compare the $\mathrm{Hg}$ content of fly ash and $\mathrm{AC}$ samples before and after thermal treatment, in order to assess the effectiveness of $\mathrm{Hg}$ removal.

- Surface Chemistry Analysis - X-ray Photoelectron Spectroscopy (XPS) in a Scienta ESCA instrument is being used to study the surface chemistry of a small selection of samples. For example, comparative studies of the surface composition of samples before and after SCR are underway to look for systematic variations in the surface $\mathrm{Cl}$ and $\mathrm{S}$ content. Furthemore, $\mathrm{Hg}$ contaminated samples are being analysed to see if the $\mathrm{Hg}$ is segregated to the material surface.

Task 4: Effect of SCR on Ash Properties. There was no activity in this task in 20042005. 


\section{RESULTS AND DISCUSSION}

\section{Task 1: Separation of Activated Carbon and Fly Ash in a Fluidized Bed}

Experiments were performed with a mixture of activated carbon and fly ash (AC/fly ash) to determine to what extent the activated carbon and naturally occurring carbon can be separated from the remainder of the mixture. The AC/ash mixture had been obtained from a pulverized coal power plant, but the proportions of $A C$ and ash in the mixture are unknown.

The experiments were carried out at room temperature in the $15 \mathrm{~cm}$ diameter fluidized bed equipped with an acoustic speaker (loud speaker) positioned at the top of the bed vessel. The settled bed depth was $8 \mathrm{~cm}$ and the sound pressure level at the distributor was $140 \mathrm{db}$. The superficial velocity of the fluidizing air was varied from 0.6 to $1.1 \mathrm{~cm} / \mathrm{s}$.

In each experiment, the bed was fluidized for 10 minutes to assure steady state conditions, and the fluidizing air was then abruptly turned off. As described in the previous section, the bed material was then removed from the bed, layer by layer.

Typical results of the segregation tests are described in the 2003 to 2004 Annual Report for this project where Figures 3, 4 and 5, taken from that report, show the sensitivity of segregation to fluidization velocity. Additional segregation tests were performed during the 2004-2005 project year and samples of AC/Ash from the top and bottom layers of the bed were analyzed for $\mathrm{Hg}$ content. Figure 6 summaries the latest $\mathrm{Hg}$ data in a graph of $\mathrm{Hg}$ content vs. $\mathrm{LOI}$ level. This figure shows very clearly the strong dependence of $\mathrm{Hg}$ content on $\mathrm{LOI}$, with the $\mathrm{Hg}$ content approaching zero as LOI approaches zero. 


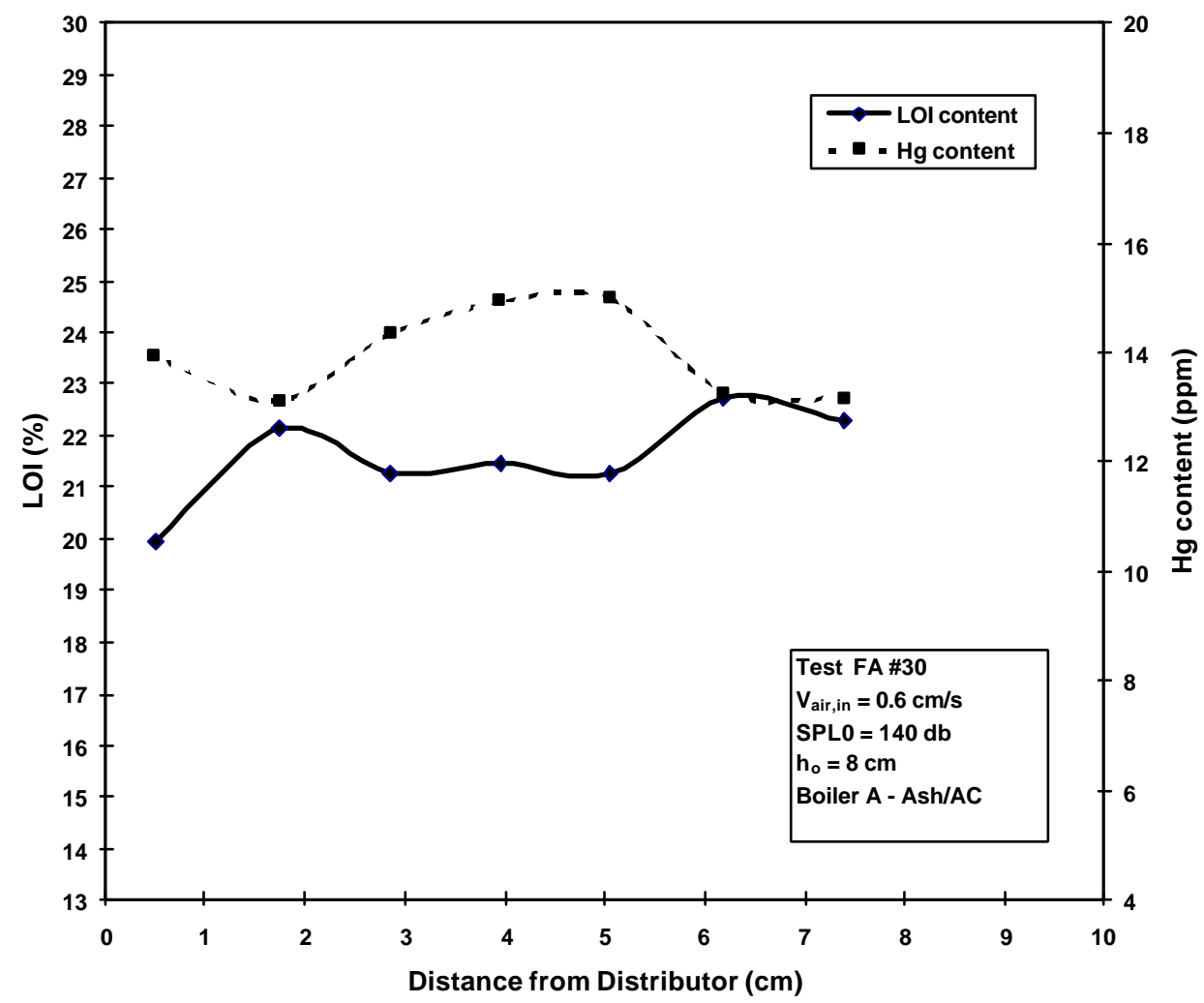

Figure 3: Vertical Stratification of LOI and Hg. $V_{\text {air }}=0.6 \mathrm{~cm} / \mathrm{s}$.

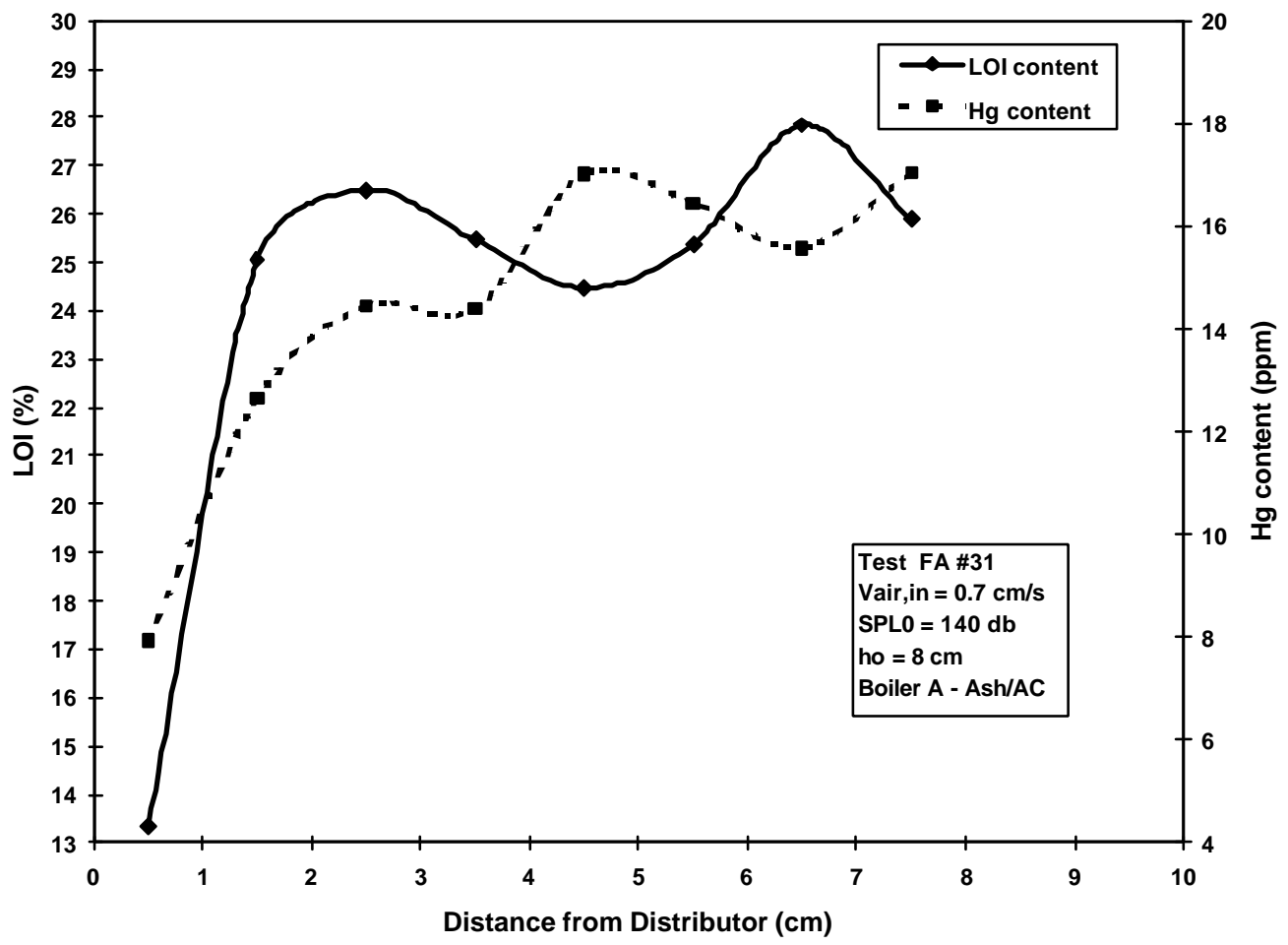

Figure 4: Vertical Stratification of $\mathrm{Hg}$ and LOI. $\mathrm{V}_{\text {air }}=0.7 \mathrm{~cm} / \mathrm{s}$. 


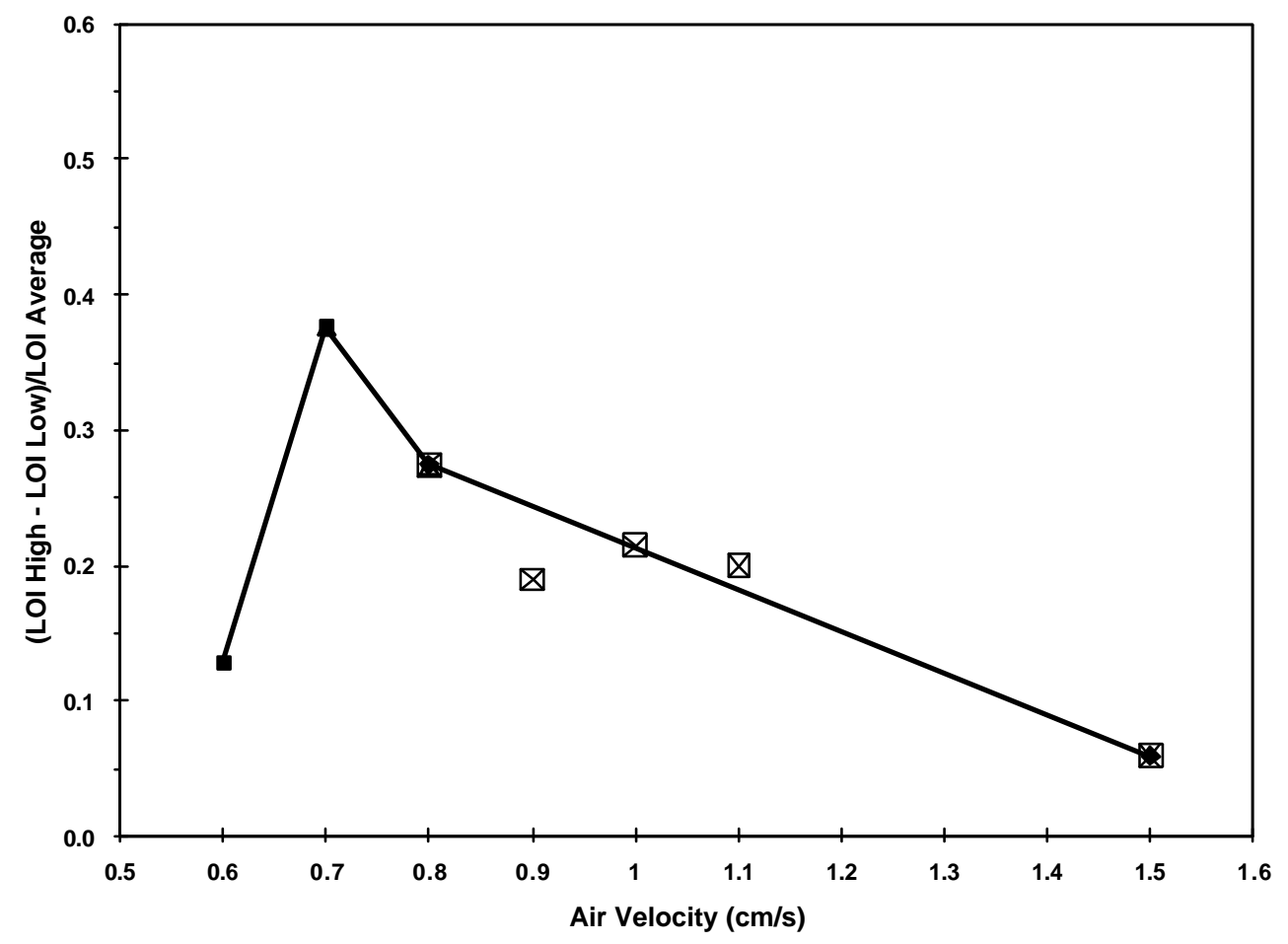

Figure 5: Magnitude of Carbon Stratification Versus Superficial Air Velocity.

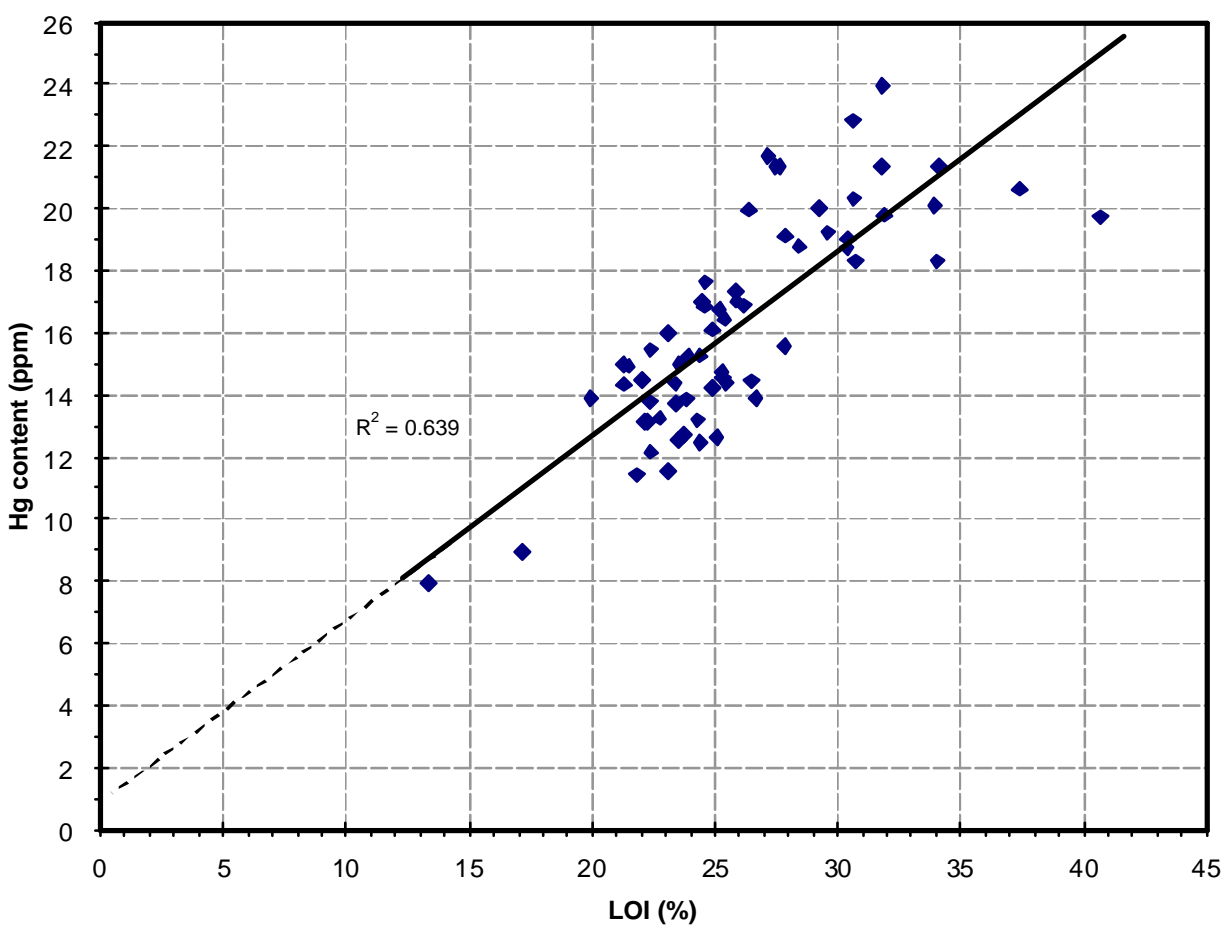

Figure 6: Hg Content Versus LOI. 
Additional Testing Underway. One activated carbon/fly ash mixture has been tested, so far, in Tasks 1 and 2. This mixture was obtained from a $\mathrm{Hg}$-capture field trial at a utility boiler. The extent of the ability to separate carbon from non-carbonaceous ash constituents in a fluidized bed will vary from boiler to boiler due to differences in particle size and density distributions. We've just received a barrel containing a mixture of activated carbon and fly ash from a $\mathrm{Hg}$-capture field trial at a second utility boiler and it is planned to perform more experiments on carbon separation and $\mathrm{Hg}$ desorption on this new material during the remaining months of the project.

\section{Task 2: Removal of $\mathrm{Hg}$ from Activated Carbon and Fly Ash}

Experiments were performed with the AC/ash mixture used in Task 1 to determine the temperature at which $\mathrm{Hg}$ is driven off. These experiments were performed in the heated fluidized bed, using the procedure described in the "Experimental" section. Once the bed was fluidized and the electrical heater turned on, an experiment lasted from one to 1.5 hours. As the temperature of the bed gradually increased with time, small samples of bed material were removed from the bed and analyzed for Hg content using the LECO Hg Analyzer.

Figures 7, 9 and 11 each depict fluidized bed temperature distributions along the air flow direction using different bed materials. Each test represents a different LOI content of fly ash/activated carbon mixture. This includes $32.6 \% \mathrm{LOI}$ from the top layers of the bed during segregation tests, $24.8 \%$ from as-received ash samples and $17.3 \%$ LOI from the bottom layers of the bed.

It can be seen from the bed temperature curves that the bottom two thermocouple readings (TC \#8 and TC \#10) are always in agreement with each other. The other four thermocouple readings decrease in the direction of air flow; with TC \#1, which is located above the bed, giving significantly lower readings than the others. The average of the bottom five thermocouple ( $T C \# 4,5,7,10$ and 8 ) readings is used as the indication of the bed material temperature during the test. The tests usually lasted 50 minutes and the highest temperatures reached were near $500^{\circ} \mathrm{C}\left(932^{\circ} \mathrm{F}\right)$. 
Figures 8,10 and 12 illustrate the relationships between bed temperature and $\mathrm{Hg}$ content of different bed materials. During a desorption test, the $\mathrm{Hg}$ content is constant for a period of time and begins to decrease at a certain temperature, depending on the initial LOI content. When the bed temperature is near $500^{\circ} \mathrm{C}\left(932^{\circ} \mathrm{F}\right)$, the $\mathrm{Hg}$ content is almost zero. The temperature at which the $\mathrm{Hg}$ content begins to decrease quickly is defined as the "critical" temperature. Figure 13 shows a linear relationship between critical temperature and LOI content, with the critical temperature ranging from 330 to $370^{\circ} \mathrm{C}$. Figure 13 also shows the bed temperature when the $\mathrm{Hg}$ content decreased to zero is between $450^{\circ} \mathrm{C}\left(842^{\circ} \mathrm{F}\right)$ and $500^{\circ} \mathrm{C}\left(932^{\circ} \mathrm{F}\right)$.

\section{Task 3a: Morphologies of Fly Ash and Activated Carbon}

The 2003 to 2004 project report contains representative SEM and TEM images of the AC/Fly Ash mixture from Boiler $\mathrm{A}$ and of pure activated carbon particles. Additional microscopy studies were performed during the 2004-2005 project year, during which the focus was on use of the Light Optical and Scanning Electron Microscopes.

Black and white optical microscopy images were taken with the camera attached to a Nikon Metaphot photo micrographic microscope. Objective lenses of 5X,10X, 20X and 50X were used in order to obtain the desired magnification levels when imaging fly ash and activated carbon particles. A length scale is shown on each image that was taken. 


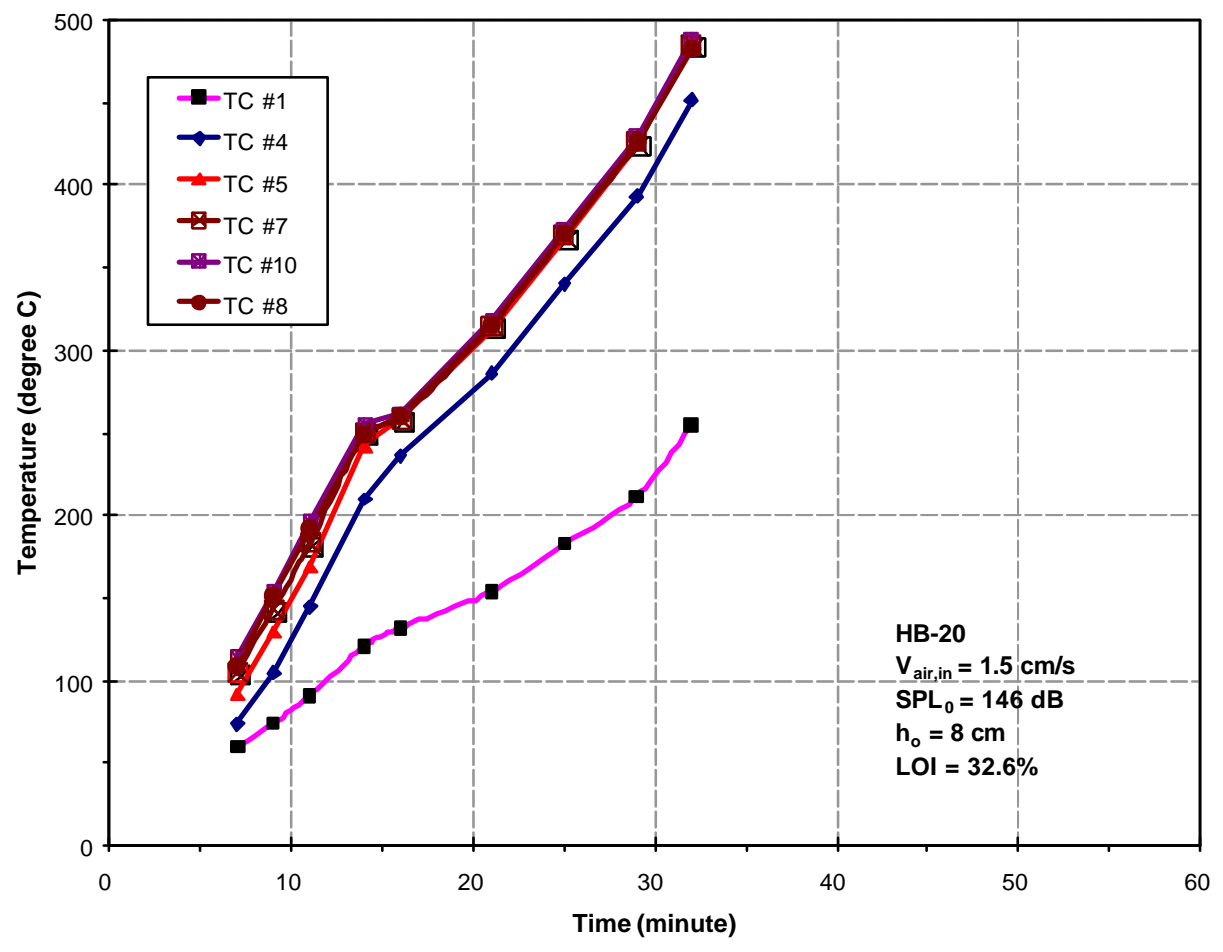

Figure 7: Bed Temperature Versus Time (High LOI).

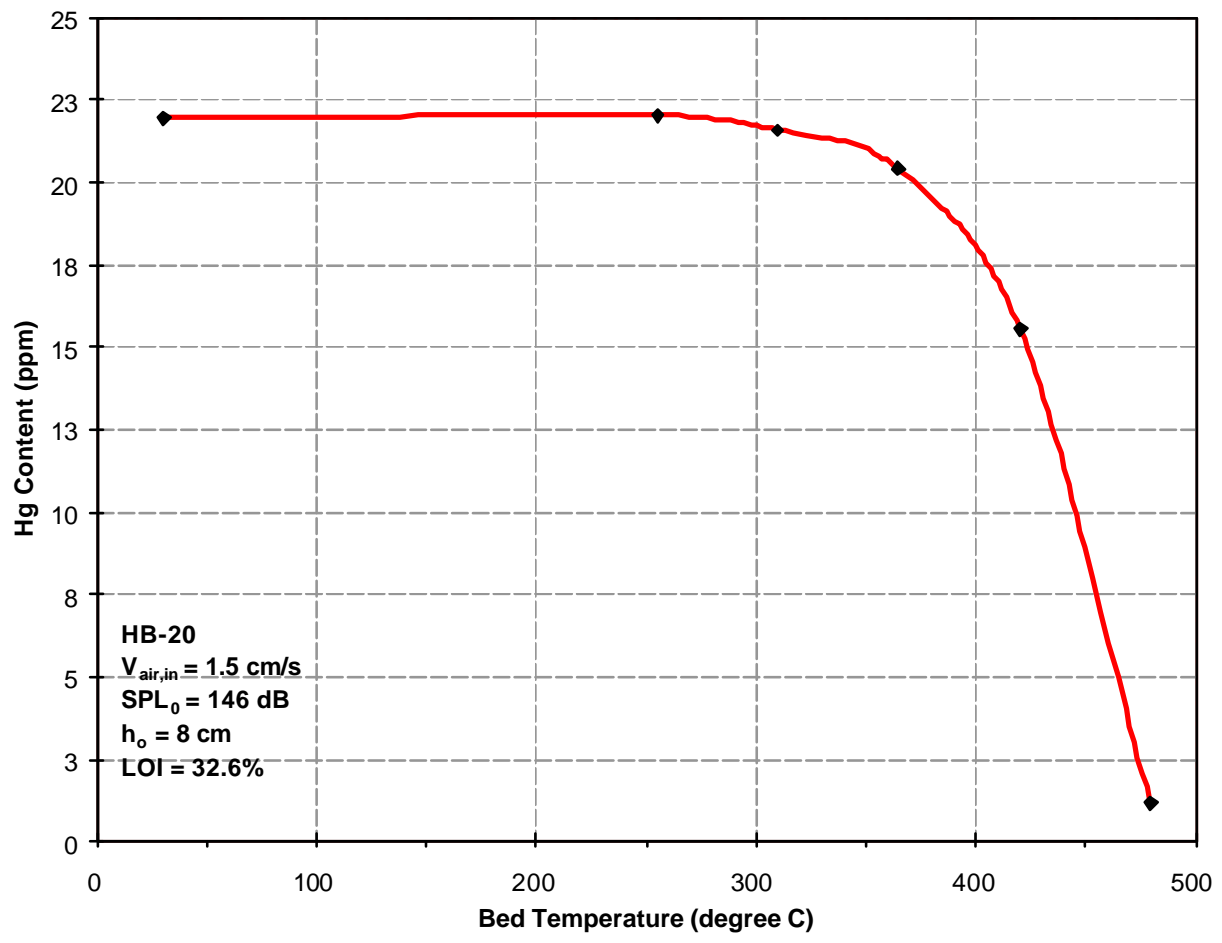

Figure 8: Hg Content Versus Bed Temperature (High LOI). 


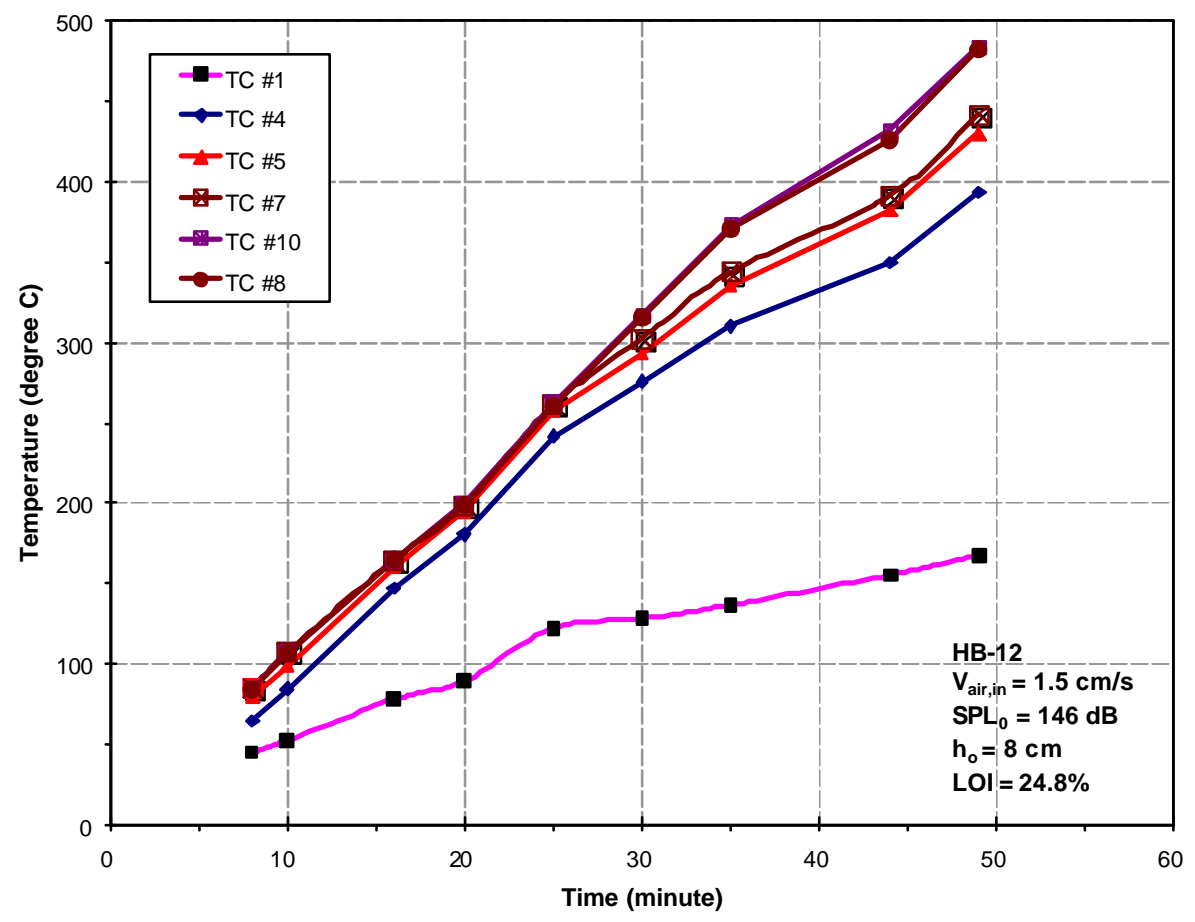

Figure 9: Bed Temperature Versus Time (Medium LOI).

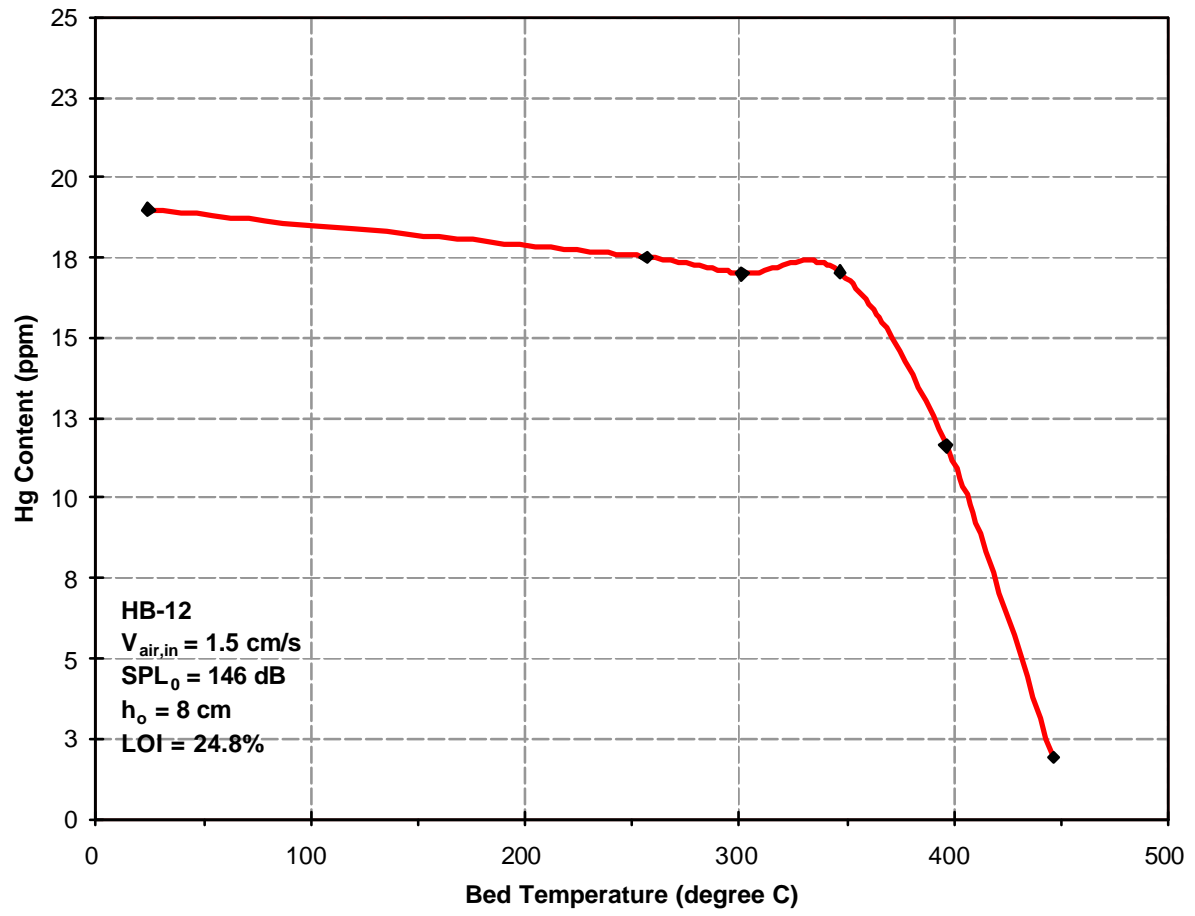

Figure 10: Hg Content Versus Bed Temperature (Medium LOI). 


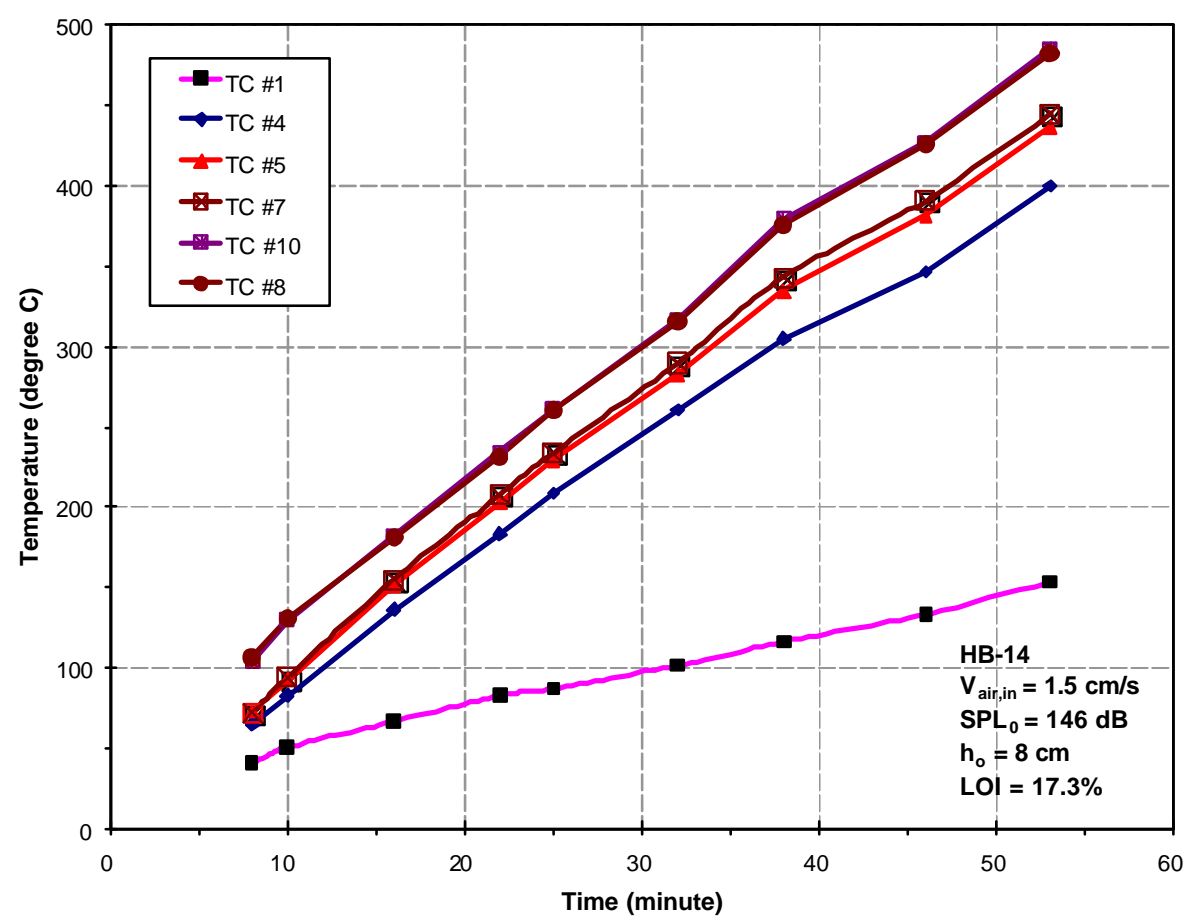

Figure 11: Bed Temperature Versus Time (Low LOI).

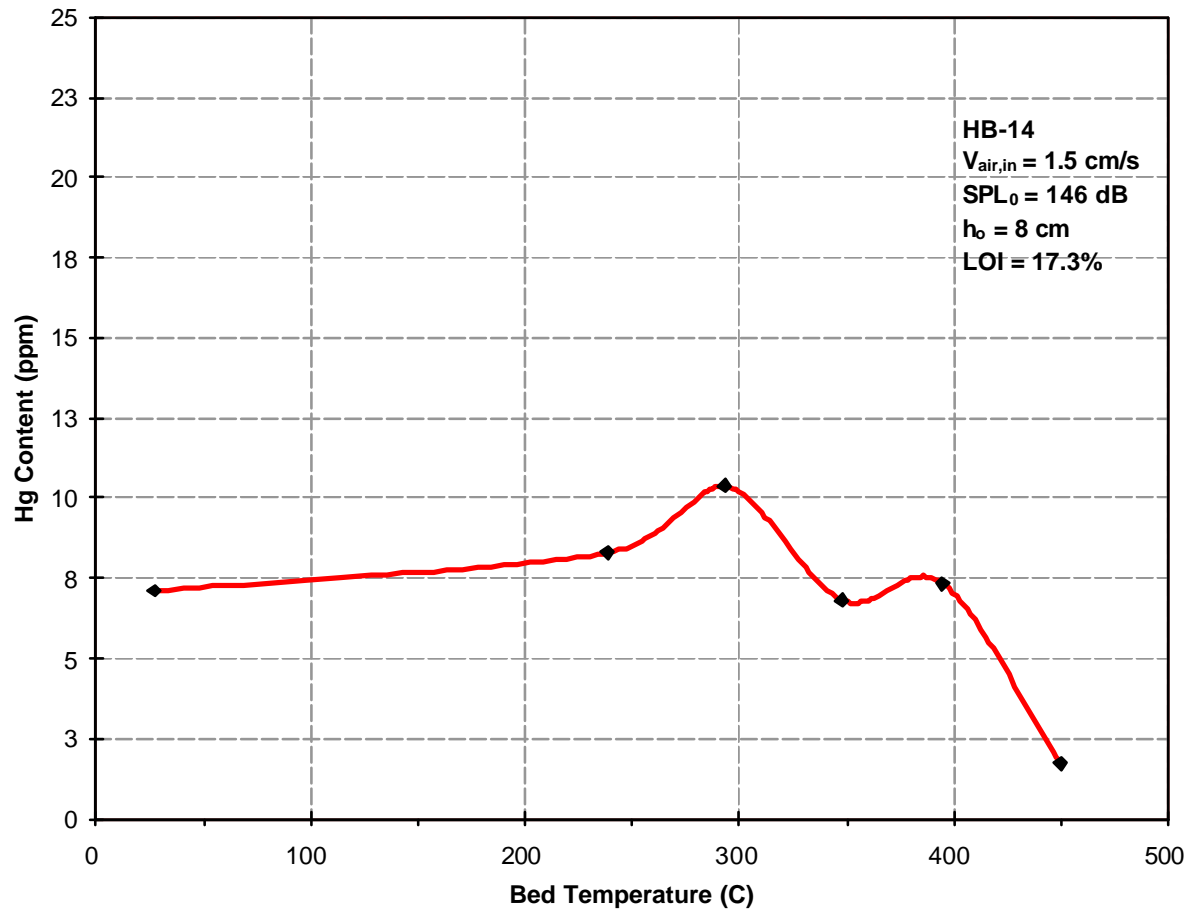

Figure 12: Hg Content Versus Bed Temperature (Low LOI). 


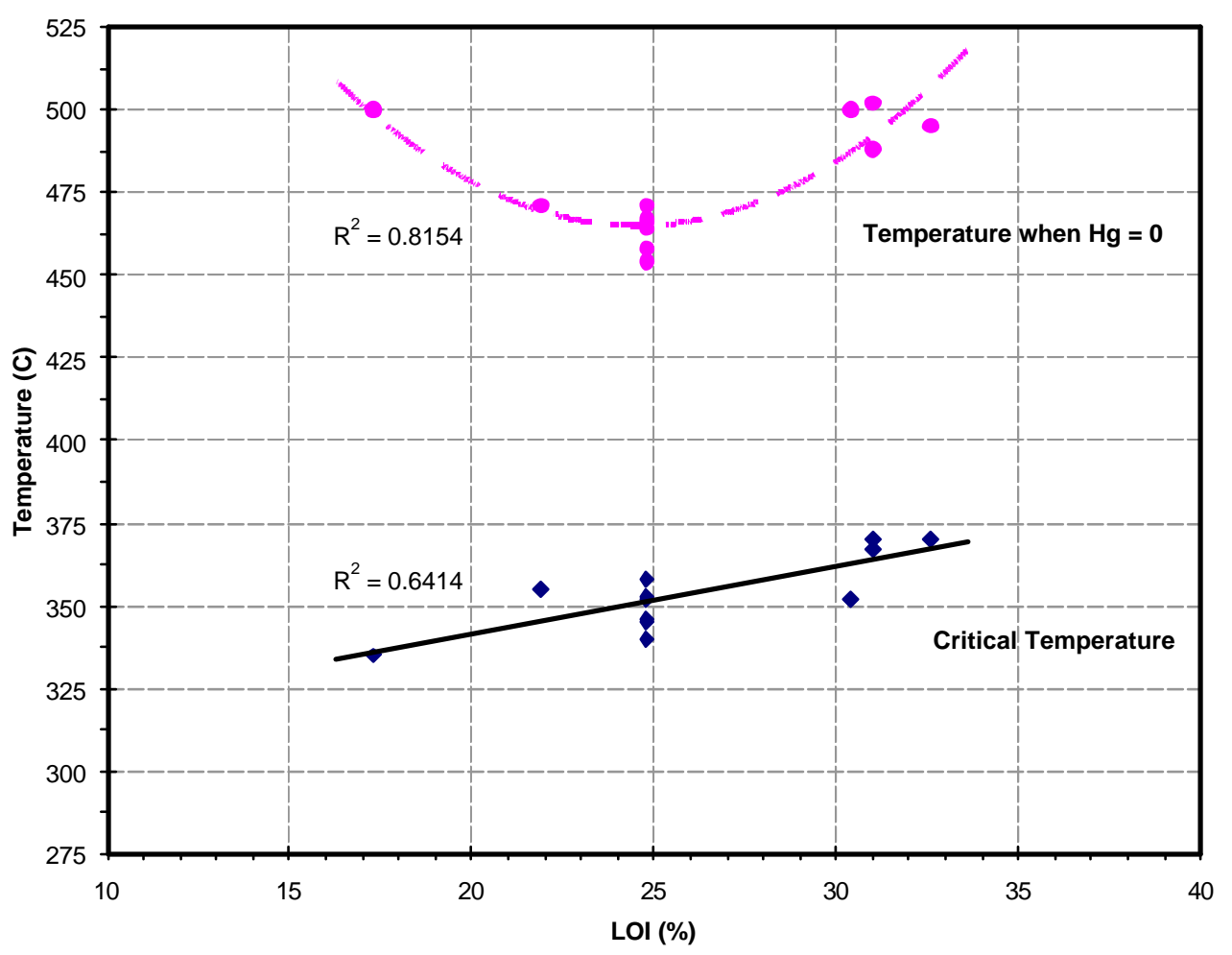

Figure 13: Critical Temperature Versus LOI.

Scanning Electron Microscopy (SEM) can be used to examine surface features at a size above 10 nanometers. The advantages of SEM imaging are high magnification, relatively simple sample preparation and the ability to investigate surface composition (with Energy Disperse Spectroscopy, EDS).

The Philips XL 30 Scanning Electron Microscopy was utilized to image samples of fly ash and activated carbon. Most SEM measurements were performed with an electron accelerating voltage of $20.0 \mathrm{kV}$; others were set at $15.0 \mathrm{kV}$. The working distances were around $20 \mathrm{~mm}$, depending on the quality of the image.

Four ash and activated carbon samples were evaluated during the 2004-2005 project year. Two were obtained from the AC/fly ash mixture after segregation in the fluidized bed. The sample from the top layer of the bed had a $27 \% \mathrm{LOI}$ and the sample from the bottom layer had a 17\% LOI (see Table 1). The other two samples were pure activated carbon $(70 \% \mathrm{LOI})$ and a high carbon content fly ash obtained from the 
electrostatic precipitator of a coal-fired boiler. All of the LOI in the latter case was due to naturally occurring unburned carbon.

Table 1

Fly Ash and Activated Carbon Samples Used in Task 3a

\begin{tabular}{|c|c|l|}
\hline Sample & LOI (wt\%) & \multicolumn{1}{|c|}{ Sample Description } \\
\hline FA-1 Top Layer & 27 & Top layer after segregation from FA-1 \\
\hline FA-1 Bottom Layer & 17.2 & Bottom layer after segregation from FA-1 \\
\hline Pure Activated Carbon & 70 & activated carbon before injection into boiler \\
\hline High LOI Fly Ash & 68 & High LOI fly ash without activated carbon \\
\hline
\end{tabular}

Fly Ash/AC Mixture Obtained by Segregation. Figure 14 shows a relatively low magnification SEM image of the top layer fly ash with $27 \%$ LOI. Compared with Figure 15 which is the bottom layer fly ash with $17 \%$ LOI, the top layer has more irregularly shaped particles (which are larger and lighter) than the bottom layer. At the same time the bottom layer has more spherical mineral content particles than top layer. This is in agreement with the fluidization theory that heavier and smaller particles tend to move to the bottom of the bed during the fluidization process while lighter and larger particles are likely to move toward the top of the bed. The white color on part of the spherical particles is because of charging effects in the SEM.

Pure Activated Carbon. Pure activated carbon particles were studied both by SEM and optical microscopy. Here the word "pure" is used compared with samples which contain both fly ash unburned carbon and activated carbon. The LOI content of this pure activated carbon is $70 \%$. The particles in Figure 16 from optical microscopy are mostly what appear to be carbon particles with an average size about $30 \mu \mathrm{m}$. Most of the particles have sharp edges which is an indication of having not going through a softening stage. Figure 17 is a high magnification of a relatively large shale-shaped activated carbon particle. 
Fly Ash With High Unburned Carbon. High LOI content fly ash from a utility boiler was used to obtain a more representative image of naturally occurring unburned carbon. The LOI content is $68 \%$ in Figure 18. Most of the visible particles are in the size range of $100 \mu \mathrm{m}$ and are of porous irregular shape and structure. From Figure 19, it can be seen that small spherical particles are attached to the surface and part of the particle looks like char. Optical microscopy images in Figures 20 and 21 also show that most particles in the vicinity are porous particles similar to the AC particles depicted in Figures 16 and 17.

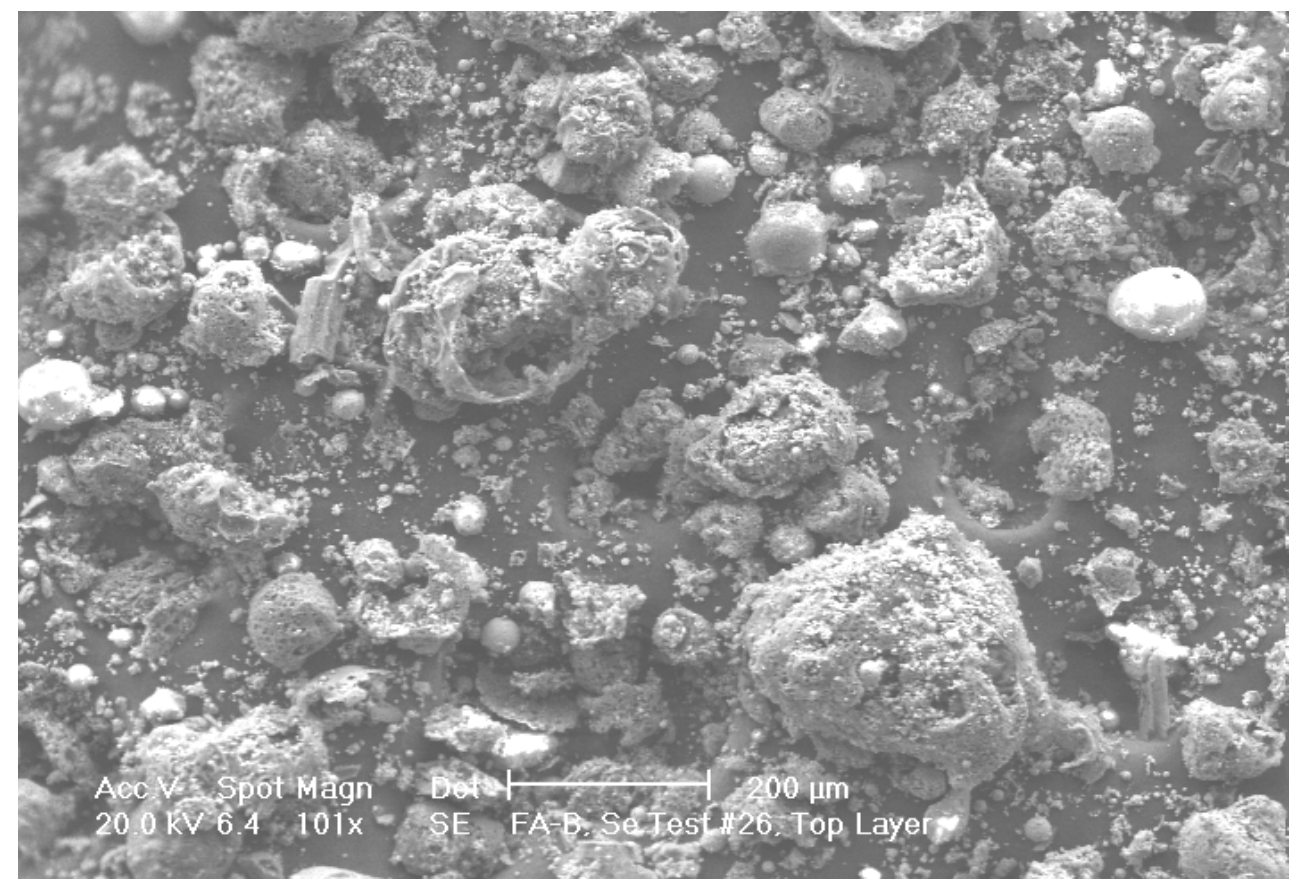

Figure 14: Top Layer of FA-1 Fly Ash Segregation. 


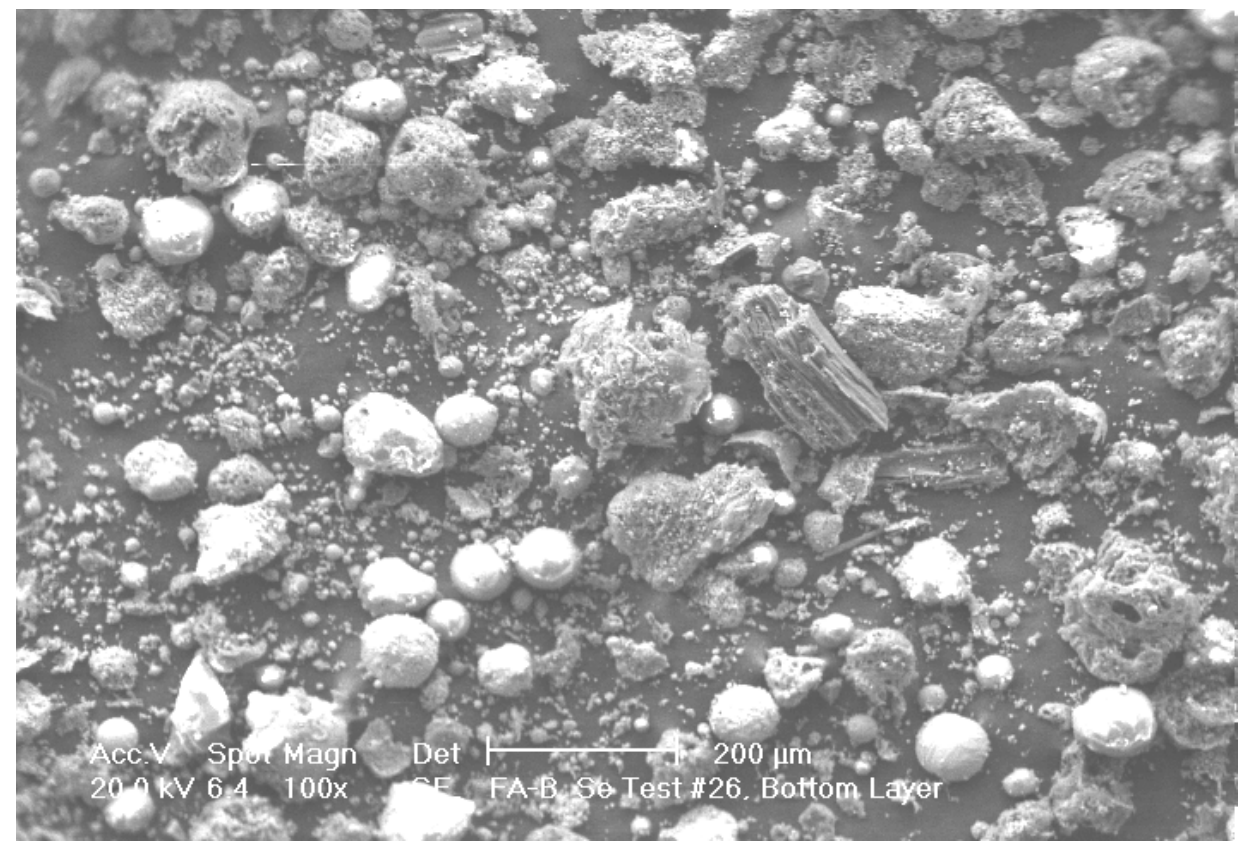

Figure 15: Bottom Layer of FA-1 Fly Ash Segregation.

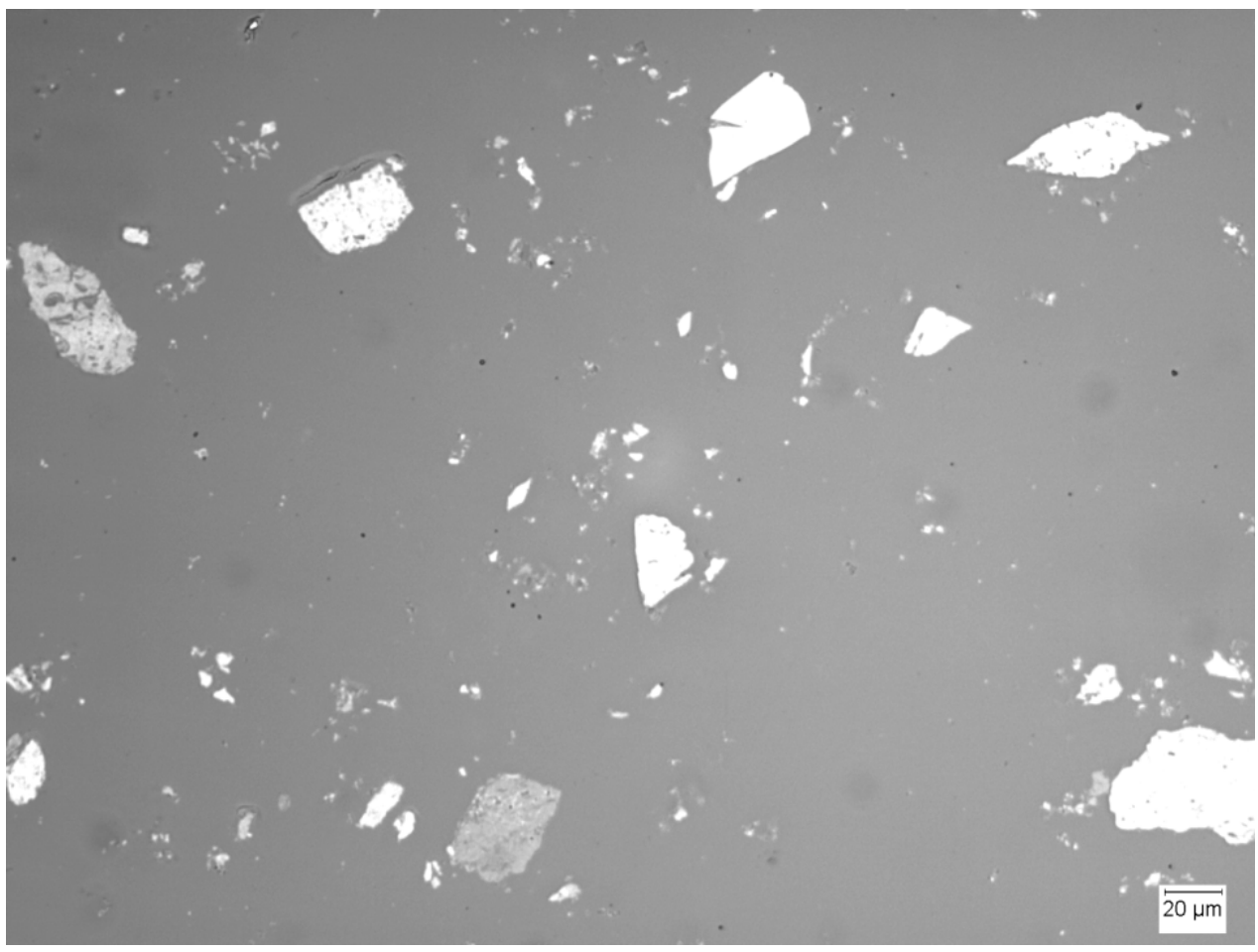

Figure 16: Optical Microscopy Image of Pure Activated Carbon Particles. 


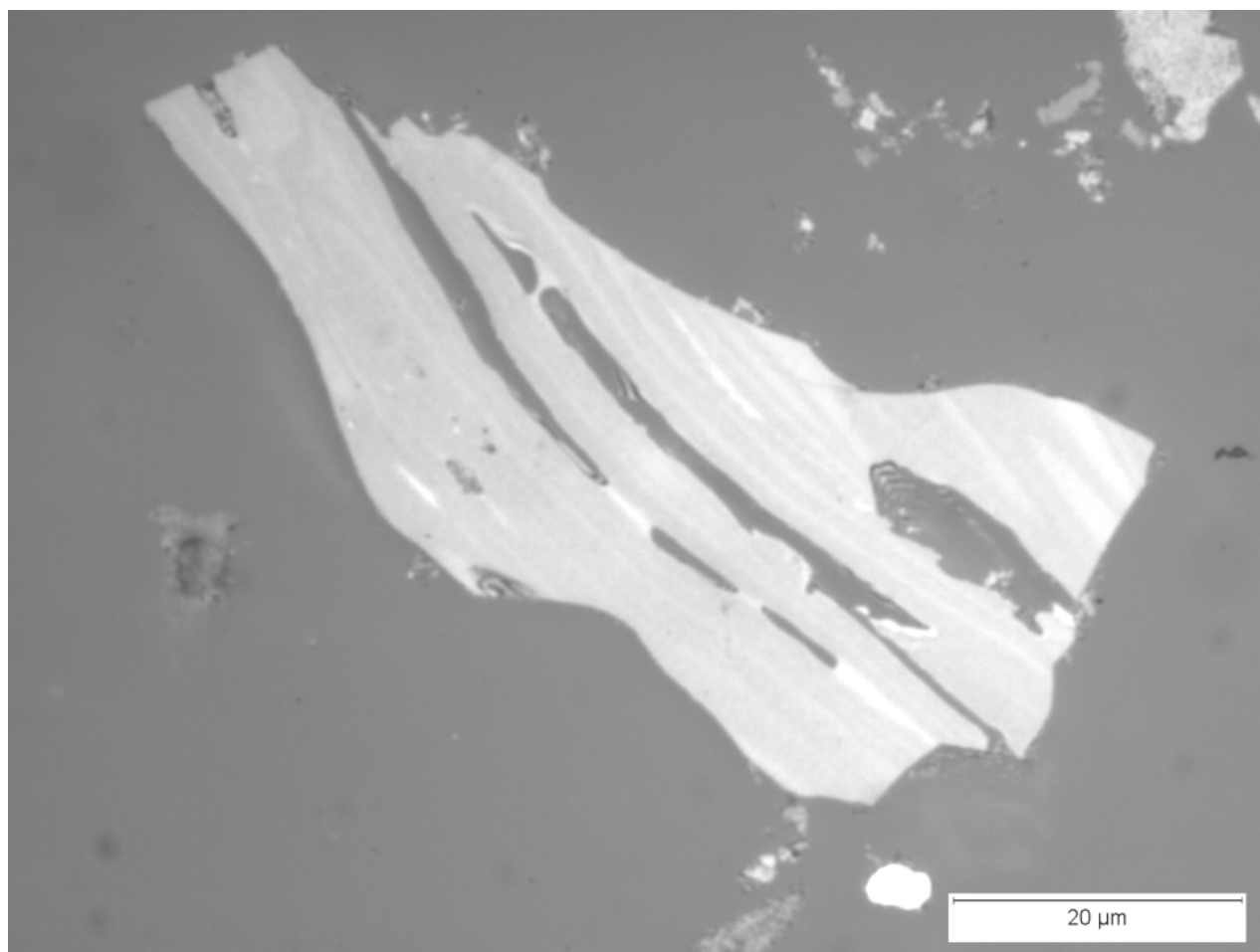

Figure 17: Optical Microscopy Image of Typical Pure Activated Carbon Particle.

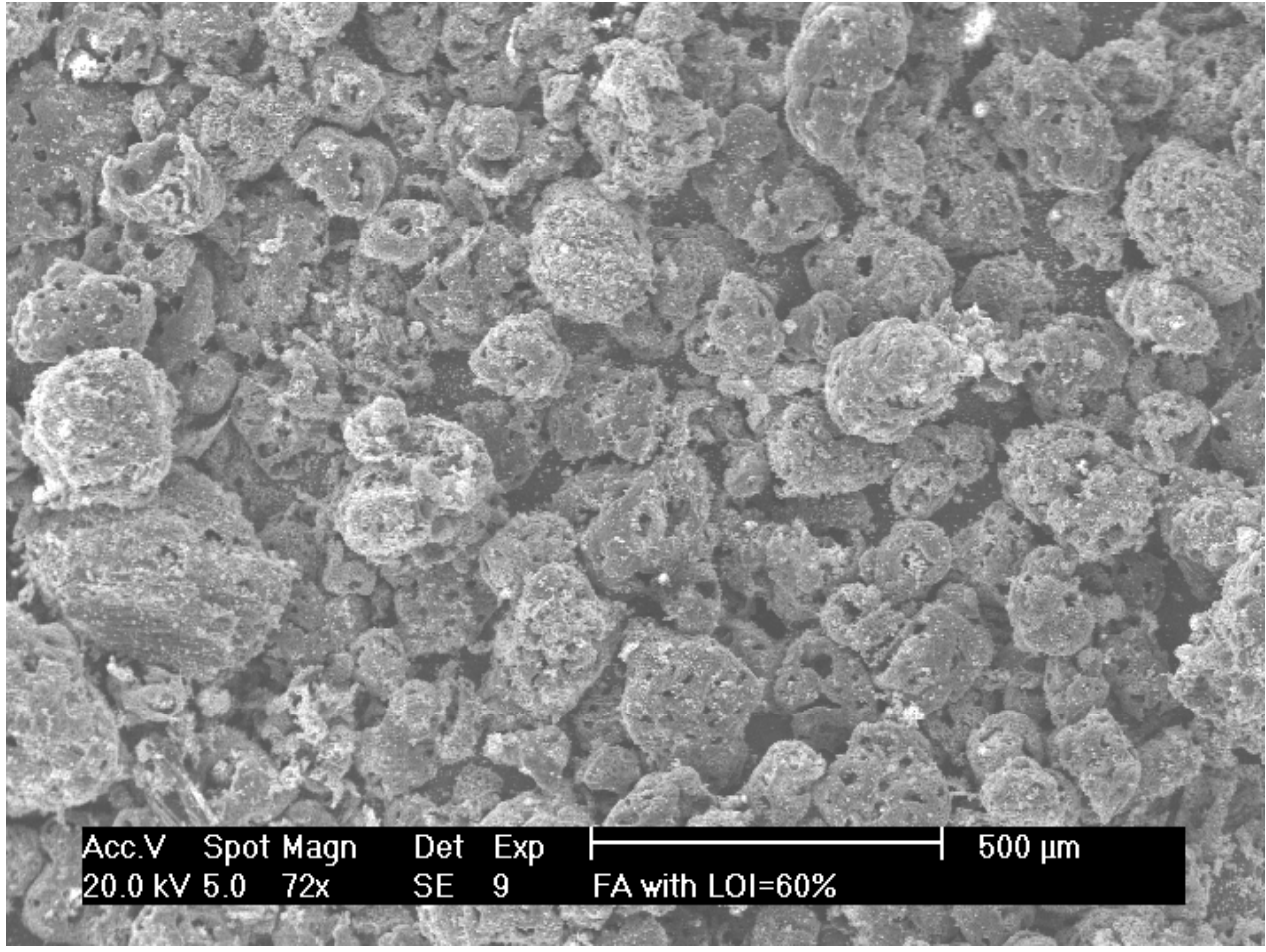

Figure 18: SEM Image of High Unburned Carbon. 


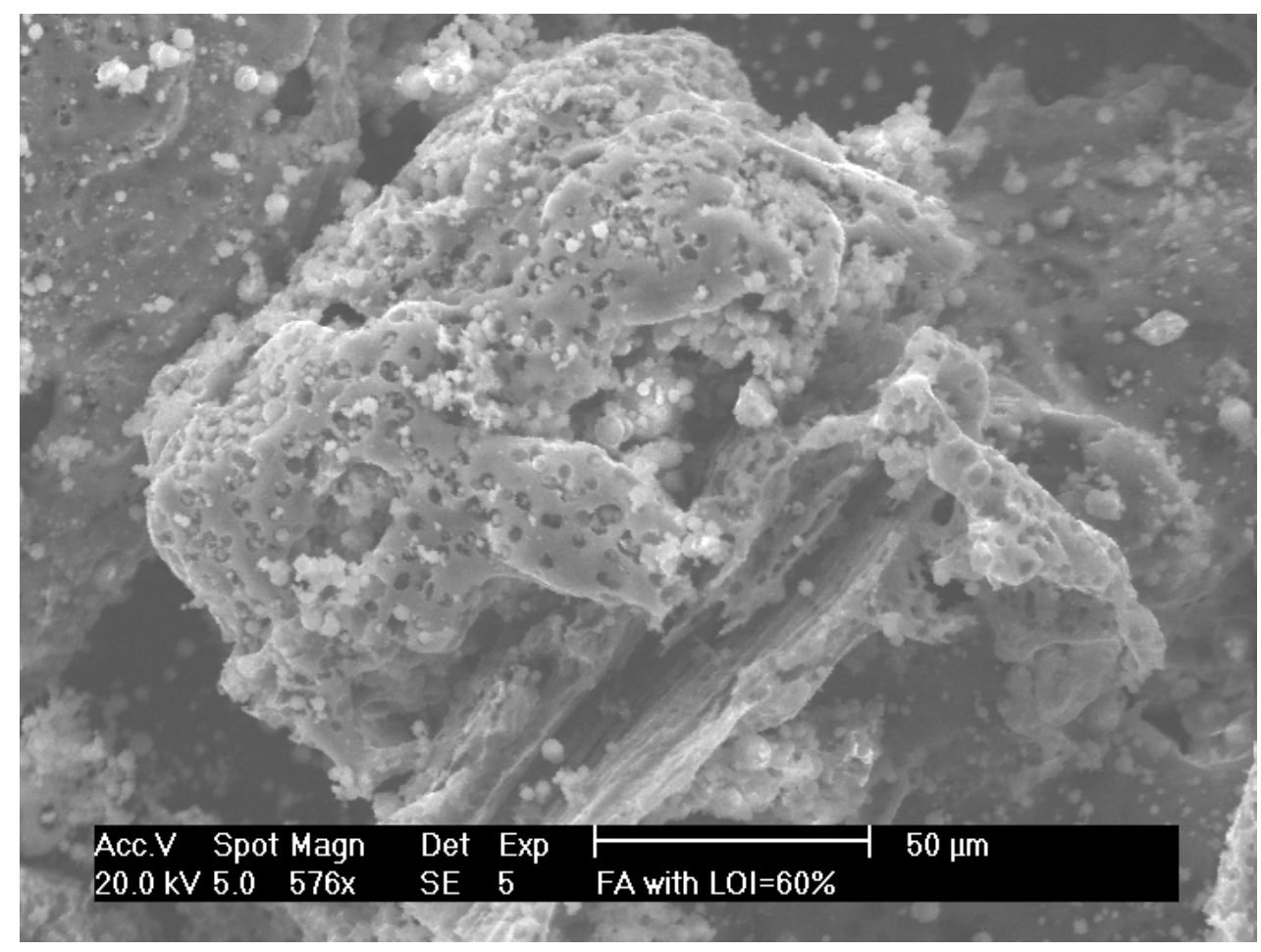

Figure 19: SEM Image of Typical High Unburned Carbon Particle.

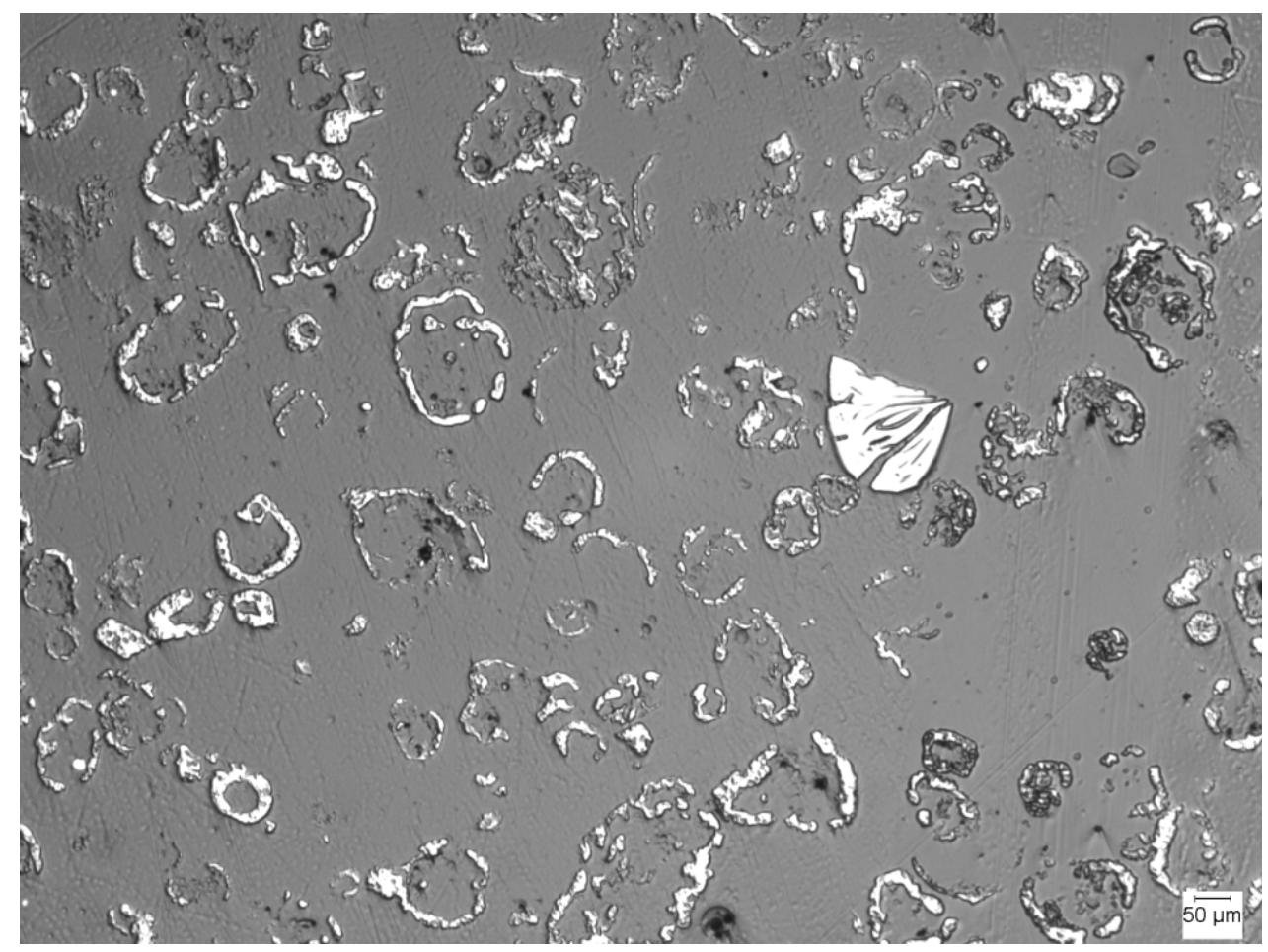

Figure 20: Optical Microscopy Image of High Unburned Carbon Particles. 


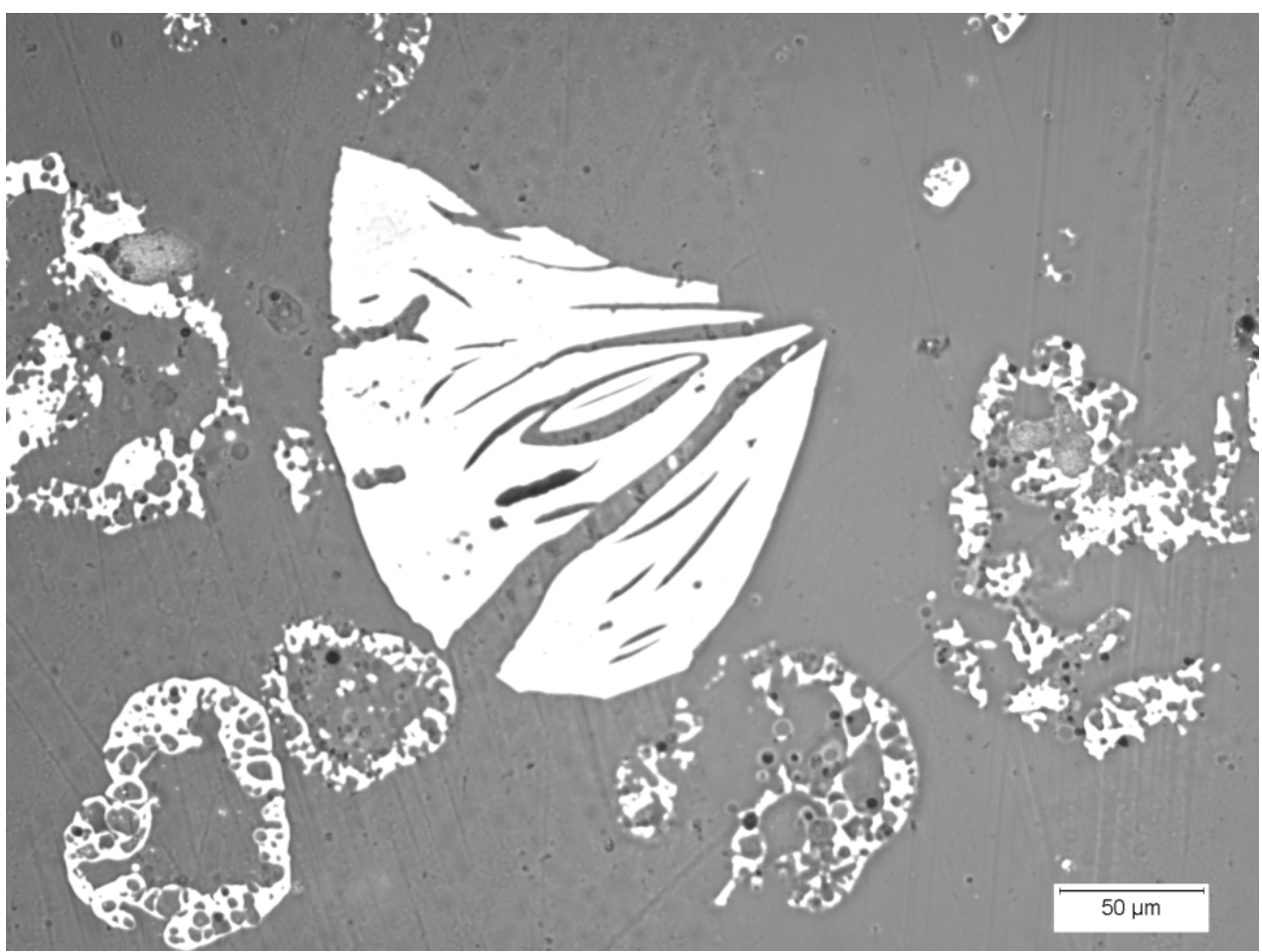

Figure 21: Optical Microscopy of Typical High Unburned Carbon Particles.

\section{SUMMARY AND CONCLUSIONS}

\section{Task 1: Separation of Activated Carbon and Fly Ash in a Fluidized Bed}

Additional separation experiments were performed on the AC/fly ash mixture to expand the range of carbon contents between the top and bottom layers of the fluidized bed. Analyses of both carbon and mercury contents of the samples obtained from these tests show a strong linear relationship between $\mathrm{Hg}$ and carbon content, with the $\mathrm{Hg}$ content approaching zero as the carbon goes towards zero.

\section{Task 2: Removal of Hg From Activated Carbon and Fly Ash}

Elevated temperature fluidized bed experiments were performed on the low carbon content mixture from the bottom layers of the fluidized bed, on the high carbon content mixture from the top layers of the fluidized bed and on AC/ash mixture with average carbon content. All behaved qualitatively the same way, with a constant $\mathrm{Hg}$ content until a critical temperature was reached and then with rapidly decreasing $\mathrm{Hg}$ 
content as the temperature was increased to higher levels. The critical temperature was found to be a linear function of carbon content, increasing from $330^{\circ} \mathrm{C}$ at $17 \% \mathrm{LOI}$ to $370^{\circ} \mathrm{C}$ at $33 \% \mathrm{LOI}$. The temperature at which all of the $\mathrm{Hg}$ was removed is in the 450 to $500^{\circ} \mathrm{C}$ range.

\section{Task 3: Morphologies of Fly Ash and Activated Carbon}

Four ash and activated carbon samples were evaluated by Light Optical and Scanning Electron Microscopy during the 2004-2005 project year. SEM studies of the fly ash/AC mixture obtained from the fluidized bed segregation experiments showed marked differences between the materials from the top and bottom layers of the fluidized bed. The top layer is dominated by large, irregularly shaped particles while the bottom layer has more spherical high-mineral content particles. This finding is consistent with the physical mechanism of segregation which results in denser, smaller particles moving downward towards the distributor and lighter, larger particles floating at the top of the bed.

Light Optical Microscopy images of pure activated carbon particles showed them to be irregular in shape and filled with voids. Light Optical Microscopy studies were also performed on a pure fly ash with high carbon content and these showed the naturally occurring carbon in fly ash has a similar internal structure to pure activated carbon.

\section{Future Experiments}

A barrel of an activated carbon/fly ash mixture obtained from a $\mathrm{Hg}$ capture test at a second boiler was obtained at the end of the 2004-2005 project year. Tasks 1, 2, and 3 analyses will be performed on the material in the coming months.

\section{REFERENCES}

1. J. Bustard, et al., "Full-Scale Evaluation of Sorbent Injection for Mercury Control on Coal-Fired Power Plants," Presented at Air Quality III, Arlington, Virginia, September 12, 2002. 
2. K. Singh, et al., "Effect of Modeling Optimal Mercury Control Choices on the Modeled Cost of Mercury Regulations," Presented at Air Quality III, Arlington, Virginia, September 12, 2002.

3. D. Laudal, et al., "Evaluation of Mercury Speciation at Power Plants Using SCR and SNCR NO${ }_{x}$ Control Technologies," Presented at Air Quality III, Arlington, Virginia, September 12, 2002.

4. Kozanoglu, B. and E. Levy, "Transient Mixing of Homogeneous Solids in a Bubbling Fluidized Bed," in AIChE Symposium Series Number 281, Vol. 87, 1991, p. 58.

5. Kozanoglu, B. and E. K. Levy, "Mixing Dynamics in a Bubbling Fluidized Bed with Binary Solids," in Fluidization VII, ed. by O. Potter and D. Nicklin, published by Engineering Foundation, 1992. 